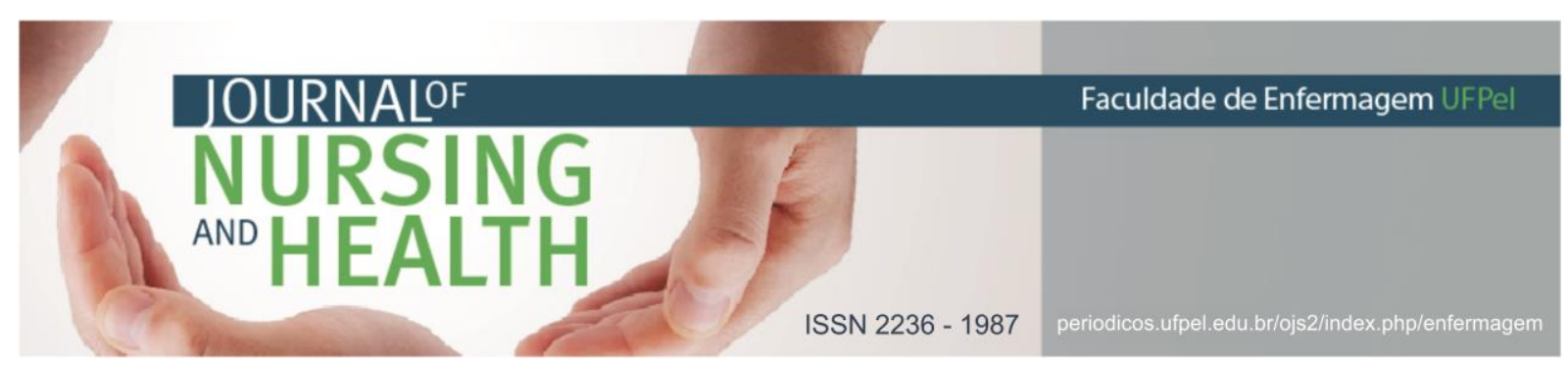

EDITORIAL

\title{
Revisión Narrativa: elementos que la constituyen y sus potencialidades
}

\section{Revisão Narrativa: elementos que a constituem e suas potencialidades}

Narrative Review: elements that constitute it and its potentialities

Zillmer, Juliana Graciela Vestena'; Díaz-Medina, Blanca Alejandra²

El avance constante de conocimiento y la creciente producción científica exigen a los investigadores herramientas que les permitan mantenerse actualizados. Frente a esta situación, la realización de revisiones de literatura posibilita la comprensión sobre determinada área y tema, además de mostrar lagunas de conocimiento que aún necesitan ser exploradas. La revisión de la literatura es definida como un estudio detallado, selectivo y, a veces, crítico que tiene como objetivo examinar lo que se ha publicado ${ }^{1}$. Hay otros tipos de revisiones, pero en este editorial pretendemos hablar de la Revisión Narrativa (RN), buscando describir los elementos principales que la constituyen y sus potencialidades.

La RN tiene como objetivo explorar, describir y discutir un determinado tema, de forma amplia, considerando múltiples factores desde un punto de vista teórico y de contexto. Sin embargo, se le señalan diversas críticas en las que se destaca que no posee un método previamente definido con criterios de selección y obtención de la información, lo que imposibilita la reproducción de los datos; no produce evidencia y respuestas cuantitativas; no plantea una pregunta de investigación específica; y la selección de los estudios y la interpretación de la información puede estar sujeta a la subjetividad de los autores ${ }^{2,3}$. Sin embargo, consideramos importante ir más allá de las limitaciones, por lo que mencionaremos sus principales potencialidades: es una estrategia que facilita la comprensión de un determinado tema, puesto que lo describe de forma amplia; suele tener fundamentación teórica y/o de contexto; permite la inclusión de diferentes tipos de información, considerando distintas fuentes; exige habilidades críticas y de reflexividad por parte del investigador. Además, posibilita el aprendizaje mediante la definición y detalle de conceptos; obtiene estudios realizados previamente sobre el mismo tema, considerando el proceso histórico y avances en el área; así como también, identifica y selecciona referenciales, métodos y técnicas para ser utilizados en futuras investigaciones.

Se trata, por lo tanto, de una revisión apropiada para fundamentar teóricamente artículos, disertaciones, tesis y trabajos de conclusión de cursos. Asimismo, posibilita la contextualización, problematización y visualización de propuestas, de nuevas perspectivas y/o el direccionamiento de un tema. Facilita a

\footnotetext{
1 Enfermera. Doctora en enfermería. Universidad Federal de Pelotas. E-mail: juliana.zillmer@ufpel.edu.br https: //orcid.org/0000-0002-6639-8918

2 Psicologa. Doctora em ciencias de la salud publica. Universidad del Valle de México. E-mail: alex_eminem@hotmail.com https://orcid.org/0000-0002-4526-3539
} 


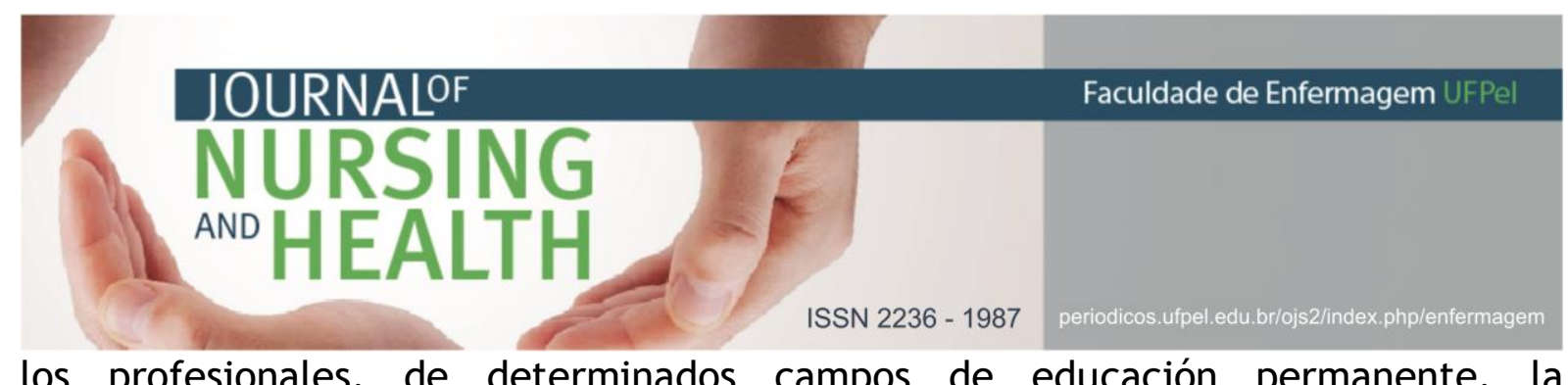

los profesionales, de determinados campos de educación permanente, la actualización y adquisición de conocimientos en un tiempo menor ${ }^{2,3}$.

A partir de lo expuesto, parece que más que comparar las diferencias entre las Revisiones Sistemáticas (RS) y las narrativas, destacando la objetividad, replicabilidad y aspectos cuantitativos de la primera, se debe reflexionar sobre la utilidad que tiene cada una. Cuestionar en qué situaciones voy a utilizar la RS y cuales la RN y de esa forma aprovechar las potencialidades que tiene cada una. Asimismo, enfatizar, que, aunque en las RN no se exponga a detalle la metodología de selección y análisis de la información, no quiere decir que no exista. Y por último, se menciona que el revisor suele ser un experto en el tema, o por lo menos, debe tener conocimientos previos. Sin embargo, también brinda la posibilidad de que el autor, por medio de la revisión, se convierta un experto en el área. Sea de una u otra manera, la RN permite que se muestre una perspectiva clara sobre determinado tema.

\section{REFERENCIAS}

1 Guirao-Goris SJA. Utilidad y tipos de revisión de literatura. Ene. [Internet]. 2015 [citado $2018 \quad$ abr 02 ; 9(2). Disponible http: / / scielo.isciii.es/scielo.php?script=sci_arttext\&pid=S1988$348 \times 2015000200002 \& \operatorname{lng}=e s$.

2 Ferrari R. Writing narrative style literature reviews. J med writ. [Internet]. 2015 [cited 2018 abr 02]; 24(4):230-35. Disponible en: https: / / www.tandfonline.com/doi/abs/10.1179/2047480615Z.000000000329

3 Byrne JA. Improving the peer review of narrative literature reviews. Res integr peer rev [Internet]. 2016 [cited 2018 abr 02];1(12):1-4. Disponible en: https: / / researchintegrityjournal.biomedcentral.com/track/pdf/10.1186/s41073016-0019-2

Data de submissão: 15/02/2018

Data de aceite: 14/03/2018

Data de publicação: 14/05/2018 